As part of the 50th birthday celebration, we are arranging to reprint 12 papers, the editor's choice, which have appeared in previous issues of the fournal. They have been chosen partly to illustrate the range and scope of the fournal over the years and partly because they are or were important in their day. More significantly, they have been chosen because they exemplify some of the best in scientific writing and can all be read with great pleasure and all who wish to communicate their observations, their ideas, or their enthusiasms would do well to study them and learn from them.

We will publish one paper each month through the year and they will appear in the order in which they were originally published.

Editor's Choice

\title{
Chronic carbon tetrachloride poisoning
}

\author{
by Alice Stewart and L J Witts
}

(British Fournal of Industrial Medicine 1944;1:11-9)

I have chosen this paper largely because of my admiration for Alice Stewart with whom I worked for a while at the University of Birmingham after she had retired from Oxford. Retirement was a purely relative term so far as Alice was concerned and she continued to work at a pace and with a zeal which left many of us amazed and exhausted. She was then working on the effects of low level radiation on workers at a nuclear submarine base but she will probably be best remembered for establishing the relation between in utero radiation and childhood leukaemia.

The study that we reprint here was undertaken in war time when "more attention had been paid to the strength of the walls and the completeness of the blackout than to the state of the atmosphere." Despite massive exposures to carbon tetrachloride it is interesting to note that the workers appeared in good health despite the severity and duration of their symptoms. Stewart and Witts describe a good many of the symptoms, which were rediscovered two or three decades later when they were referred to as the "solvent syndrome"; these include loss of mental agility, inertia, memory deficits, depression, irritability, excessive fatiguability, and drowsiness. Another striking observation - and one which might have been heeded by later investigators - was "the speed with which symptoms disappeared when workers were removed from the plant."

Another point of interest was the appearance in the workforce of an antipathy to any smell that reminded them of the chemical works. The workers developed a sensitivity to carbon tetrachloride, so much so that a plant chemist (who later became an important figure in occupational medicine in his own right) stated that "I have now developed a conditioned reflex and the thought of setting about a job which involves handling the stuff is enough to make me vomit." This kind of response, and particularly the cross-sensitivity to other pungent or acid smells is commonly seen in individuals who have real or perceived high exposure to solvents and other odorific chemicals. But that is a topic for another occasion. 